\title{
Influence of Groundwater Table on Beach Profile Dynamics
}

\author{
G. A. P Gampathi and Soon Chan
}

\begin{abstract}
A systematic study of the influence of coastal groundwater table on beach profile changes have been conducted experimentally. The purposes of this study were to investigate experimentally the influence of elevated groundwater table on beach profile changes and to investigate the function, performance and optimum method to install a coastal drainage system. The beach responses to different elevated groundwater tables and porous layers were examined and compared with a normal beach.
\end{abstract}

It was found, from the study, that the elevation of the groundwater table has a major influence on the beach profile changes. Beach erosion, by erosive waves, was enhanced and beach accretion by accretion waves was reduced or erosion types convert to accretion types. The mechanism and quantitative variation of sediment transport was directly related to the elevation of groundwater table relative to mean sea level.

The beach erosion by erosive wave can be reduced or erosive wave can convert to accretion wave by installing drainage layers inside the beach. It also can increase the effect of a recovery wave on the beach. The effectiveness of the system depends on the speed of the infiltration of water through sand to the porous layer (location of porous layer relative to beach face), depth of scouring and gradient of percolation towards onshore.

\section{Introduction}

In a permeable beach, we can expect an internal flow within the beach face due to the ground water table level inside the beach or wave run up. If these internal flow forces (seepage forces) are large enough to destabilise the sand particles, it may affect the sand transport resulting in beach erosion. When waves run up beyond the berm crest during a storm, the sea water stays for a good while on the horizontal area of the berm, which accelerates infiltration of water into the beach. As a result, the local elevation of the water table becomes higher, and water exfiltrates through the surface of foreshore. The seepage level of water corresponds to the critical level of berm erosion. This situation may further enhance with an elevated natural groundwater table.

An elevated groundwater table reduces the stability of the beach due to saturation of sand and increasing the forces from seepage. So, the combine action of seepage and saturation may influence beach erosion.

\section{Previous Studies}

The drainage capacity of a beach face is lesser than the infiltration capacity. Therefore, an elevated groundwater table is present due to wave action. The elevation of this water table is a function of wave conditions and the porosity of beach material. Hong-Yoon Kang and Peter Nielsen (1996) developed a mathematical model to find out the elevation of wave induced groundwater table and compared the results with a field experiment. Travis E.Mason and Diane P. Horn (1995) also developed a numerical model to find out the elevation of wave induced groundwater table.

Studies on rapid water table fluctuations within the beach face by Ian L. Turner and Peter Nielsen (1996) found that a large magnitude water table fluctuation within the swash zone is caused mainly by capillary effects. Field measurements and careful consideration of saturation and porepressure characteristics, within the beach face, demonstrate that rapid water table rises are associated with minute (downwards) swash infiltration rather than rapid (upwards) groundwater exfiltration.

Rapid water table rise and fall is the response to a local jump in pore-pressures within the capillary fringe, caused by the alternating appearance and

Eng. G.A.P.Gampathi, AM (IESL), B.Sc.Eng. (Hons) (Peradeniya), M.Eng. (NUS), Civil Engineer, Department of Civil Engineering, Naval Dockyard Trincomalee. C.E.Soon, M. (IES), M.(IEEE), M. (AGU), BEng.(Hons) (NUS), M.Eng (NUS), ScD. (MIT), Senior Lecturer in Engineering, Department of Civil Engineering, The National University of Singapore. 
disappearance of meniscuses at the sand surface. From these observations they have concluded that the rapid water table fluctuation within the beach face increase the effective weight of sediment. Finally, it is intriguing to note that, rather than rapid water table fluctuations within the beach face being associated with an increase in sediment mobility; the opposite may be the case.

Capillary effects provide a mechanism for the propagation inland of high-frequency sea level oscillations, The existence of a capillary fringe above the beach water table has been confirmed by field measurement (e.g., Turner, 1993). As the water table fluctuates, the pressure distribution above the water table will change, and thus an apparent local water table exchange across the water table occurs.

The water table can fluctuate within the capillary fringe without much water movement since the water saturation inside the capillary fringe is close to unity. It is clear that under this mechanism the water table responses to sea level oscillations are simultaneous; that is, there is no phase shift between the local water table fluctuations. However, the amplitude of the fluctuation is damped inland. If the porosity of sand is small and the frequency of oscillation is large, capillary effect is dominant and the water tables will respond according to capillary mechanism.

From previous studies, it is noted that there are two different groundwater table zones. One of them is formed due to difference in exfiltration \& infiltration capacity of the beach and the other due to formation of capillary fringes above the wave induced groundwater table.

Laboratory experiments on the effect of gravity drainage systems on beach stabilisation, by Horisohi Kanazawa, Fumihiko Matsukawa and lowa Hasegawa (1994) found that draining of groundwater table causes beach accretion. This may be due to increasing of the stability of the beach by reducing the area of saturation and also reducing the seepage though the beach face, the faster seepage from drainage layer causes deposition of sediment on the beach, hence accretion. Field experiments by Kazumasa Katoh (1995) also showed some accretion on the beach.

Grant (1990) appears to suggest that the mechanism for fluidization of sand grains on the beach surface may be due to general groundwater outflow from the beach associated with a high water table. A number of researchers have considered this effect but none has found convincing evidence of its importance in sediment transport. For example, Tae-Myoung Oh and Robert G. Dean (1996) performed laboratory experiments and numerical modelling to examine the effects of control of the groundwater table on beach profile dynamics. It was recognised that the effect of upward flow on sediment transport appeared to be small compared with the effects of a steep slope. However, most of these studies involved either scaled-down experiments in the laboratory or field monitoring \& observation.

Although several researches have considered the effect of an elevated groundwater table on sediment transport on a beach face, they have not noticed convincing evidence of its importance in sediment transport. But several factors exist for enhancing sediment transport. Therefore, it is necessary to understand the physical mechanisms that link beach groundwater and sediment transport and to improve the understanding of the function, performance and optimum location of a beach dewatering system.

The main objectives of this current study are to investigate the beach responses to erosive (erosive: take sediment from onshore and deposit it offshore) and accretion (accretion: take sediment from offshore and deposited it onshore) waves with different elevated groundwater tables and to find out the function, performance and optimum location of a beach dewatering system.

\section{Elevated Ground water table experiment}

A laboratory experiment was conducted to investigate the effects of the groundwater table on beach profile dynamics. Four series of experiments were conducted in a wave tank at four different water table levels while the other conditions were fixed to constant values with regular waves. Experimental set ups are shown in Figs. 3.1(a) and (b).The experiments were conducted in a wave tank, which was approximately $40 \mathrm{~m}$ long, $0.9 \mathrm{~m}$ wide and $0.9 \mathrm{~m}$ deep. A box of gravel composed of gravel with medium size $25 \mathrm{~cm}$ has been constructed at the end of the tank to support the beach and to establish constant groundwater tables at the backside of the beach. The Total length from the 

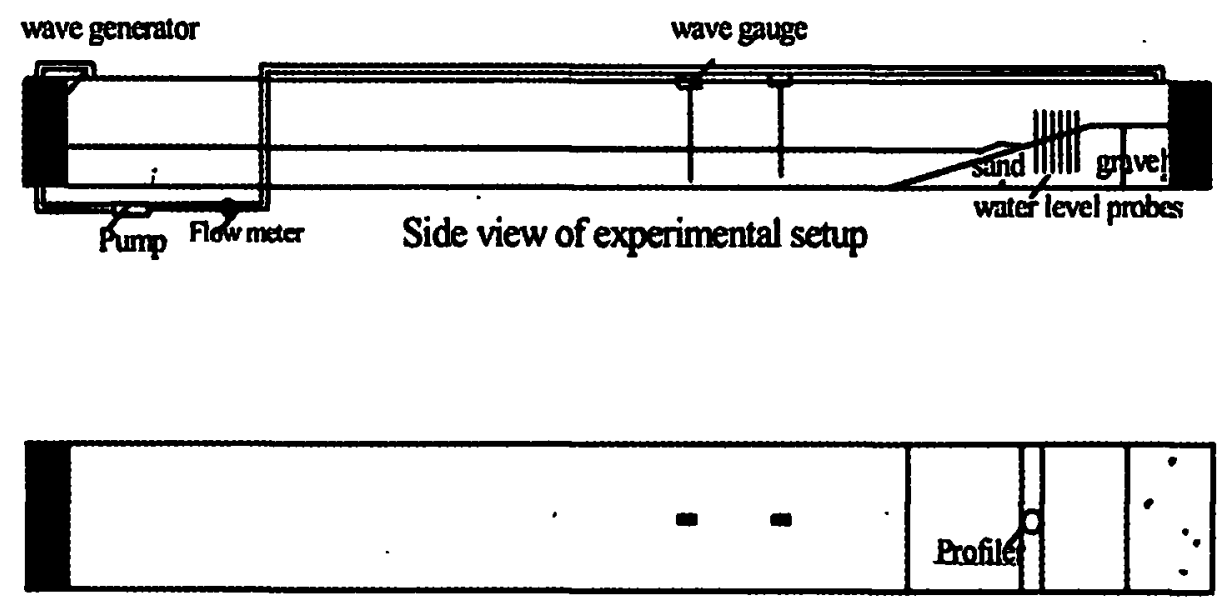

Plan view of experimental setup

Fig 3.1 (a) Experimental Layout for Elevated Ground water table experiment

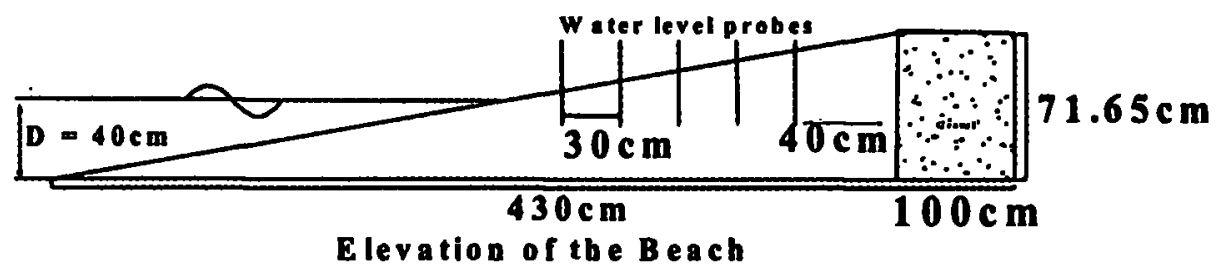

Fig 3.1(b) Experimental Layout for Elevated Ground water table experiment

end of the box of gravel to the end of the tank was $3 \mathrm{~m}$. The purpose of keeping this space was to maintain constant groundwater tables at the backside of the beach without any influence from small fluctuations of pumping rate. A sloping beach was formed with initial slope 1:6 and composed of fine sand with mean diameter of $0.5 \mathrm{~mm}$.

Five numbers of water level probes were installed in a space of $30 \mathrm{~cm}$ from the shoreline. Probes were placed inside perforated PVC pipes that were covered with fine plastic mesh. The response times of these gauges were calculated with fast moving waves. With these results, it is assumed that probes were accurate enough to measure the fluctuation of the groundwater table inside the beach. But it is understood that there may be small differences of magnitude and time lag with this arrangement. Therefore, we were referring to the mean groundwater table. At the beginning of the experiments, initial water level of each probe was recorded using a point gauge and then the gauges were adjusted for zero. All the gauges were cabled to a single personal computer, which was programmed to store data at $10 \mathrm{~Hz}$ for 3 hours. Workbench PC software was used for programming. The software is mainly for data acquisition, process control and analysis.
The higher water table was established by pumping water from the front of a wave paddle to the backside of the beach. Initially, the water level in the wave tank was approximately raised up to the required level. Then the water circulation system that comprised of a pump, valves and a flow meter was started. After allowing the groundwater table to equilibrate to the required level additional water was pumped into the tank to keep the required level. Small variation of groundwater table was adjusted by the smooth changing of flow rate to maintain the desired level and allow for steady, conditions.

Experimental conditions were designed to simulate the beach response to accretion and erosive waves, as the water depth at the toe of the beach slope was $0.40 \mathrm{~m}$.

The experiment was conducted at four different groundwater table levels, $0 \mathrm{~cm}, 5 \mathrm{~cm}, 10 \mathrm{~cm}$, and $13 \mathrm{~cm}$ respectively. Flow rates of $4.5 \mathrm{l} / \mathrm{min}, 7.5 \mathrm{l} /$ $\mathrm{min}$ and $8.0 \mathrm{l} / \mathrm{min}$ were maintained to establish above elevated groundwater tables respectively. The total duration of each experiment was 3 hours. The duration of experiments was determined based on an assessment that the beach profiles were near equilibrium and would not significantly change beyond this text duration. 
In the experiments with and without higher groundwater table, changes of beach profiles were measured along three lines of the beach, which were equally spaced. The bed elevation was monitored using an electronic profile indicator ( $\mathrm{Pv}-07)$. The movement of the bed profile indicator was controlled manually.

The bed profile indicator consisted of a probe, placed vertically in water. A servomechanism maintained the tip of the probe at a constant distance above the bed. A potentiometer was attached to the probe to be translated into a voltage signal. With the movement of the carriage onshore and offshore the bed profiles could be recorded continuously. The data were recorded as voltage using a multimeter and converted, according to the calibration, for obtaining the profiles. The average profiles were calculated taking the average of three lines.

The bed profile indicator was adjusted for balance, slip coupling and sensitivity before being used in the experiments. Calibrations were carried out both before and during the experiments. The beach profiles were monitored at initially, 30 minutes, 90 minutes and 180 minutes for each experiment.

A series of initial experiments were conducted, for different waves, to find out the beach responses to each wave condition. Finally, 6 regular waves (wave conditions are presented in 5.3.1) were selected considering beach accretion and erosive condition. Two capacitance type wave gauges were fixed $8 \mathrm{~m}$ away from the toe of the beach in a space of $4 \mathrm{~m}$. The wave parameters and wave reflections were monitored with the help of an oscilloscope. In addition to these two gauges, a same type of gauge was fixed with a carriage to monitor wave reflection.

We have paid more attention to keep the same initial condition of beach for each run. After each run, the next run was started with the same initial condition. To keep the same initial condition, the top layer of eroded beach was scooped out up to $10 \mathrm{~cm}$ from the initial beach surface. The same weight and volume of dry sand was used to fill the scooped out volume falling from a constant height.

All the series of experiments were followed by at least one consecutive run to evaluate the repeatability of the results. During the experiment a digital video camera was used to observe wave breaking, sediment transport and characteristics of run up.

\section{Beach dewatering system.}

Laboratory experiments were conducted to investigate the functions, performance and optimum method to install a coastal drain system.

Four experiments were conducted using the setups as shown in Figs 4.1(a) to (d). Different drainage layers were built inside the beach to simulate beach responses for varying location and shape. Three of these layers were parallel to the beach face and the other was inclined 1:4:8. The layers, which were parallel to the beach surface, were $15 \mathrm{~cm}, 10 \mathrm{~cm}$ and $5 \mathrm{~cm}$ below the surface. The inclined layer was $10 \mathrm{~cm}$ below the beach surface at the starting position and reducing upward to keep the required slope.

The porous layers were composed of $25 \mathrm{~cm}$ mean diameter of gravel. In order to prevent sand from entering the drainage layers and to keep the stability, the layers were covered with wire mesh and synthetic mesh. The main function of the layers was to drain infiltrating water from the beach face. Each of these drainage layers was connected with a horizontal layer. The function of the horizontal layer was to transfer infiltrated water to the backside of the beach. Four drainage pipes were extended from the backside of the beach towards the offshore to drain from backside of beach to the offshore.

These pipes were installed along the bottom of the flume at equal spacing. The purpose of this set up was to circulate draining water quickly without affecting the approaching waves. Regular waves were generated, as in the first part of the experiment, to simulate the beach profile with and without drainage layers. The initial beach slope was 1:6. The beach was formed with sand composed of mean diameter of $0.5 \mathrm{~mm}$. The same procedure, as in the first part of the experiment, was carried out to maintain the same initial condition for each run but with different scooped thickness. In the experiment, changes of beach profiles were measured along three lines.

During the experiment, some of the runs were repeated to check the repeatability and a video camera was used to observe the mechanics of sediment transport and run up. 
4.1 Experimental Layout for Dewatering System

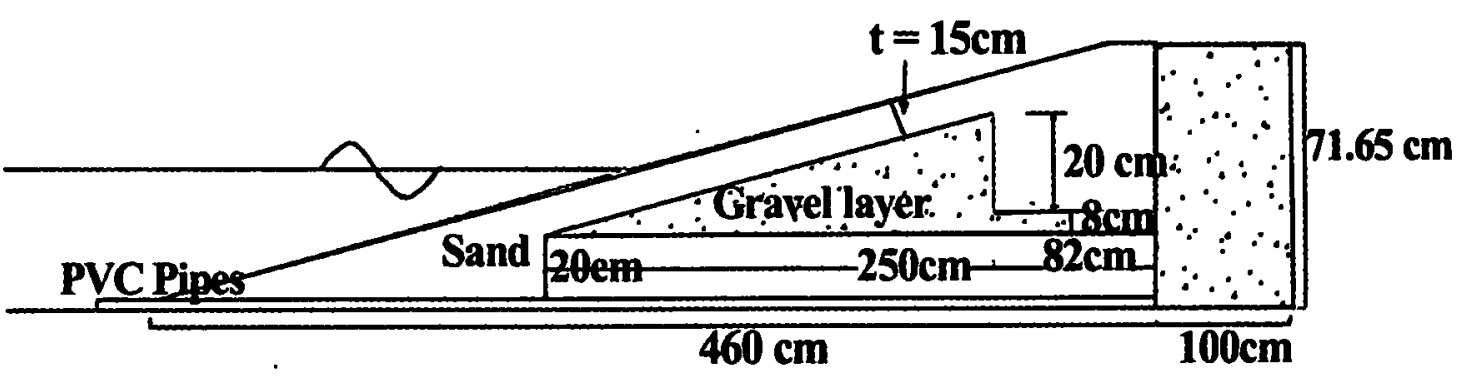

Fig 4.1 (a) $15 \mathrm{~cm}$ thick sand layer above the gravel layer

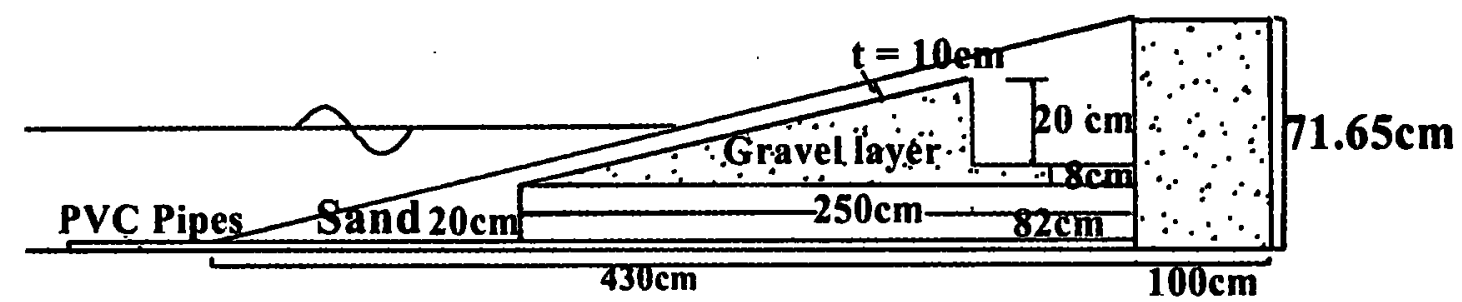

Fig 4.1 (b) $10 \mathrm{~cm}$ thick sand layer above the gravel layer

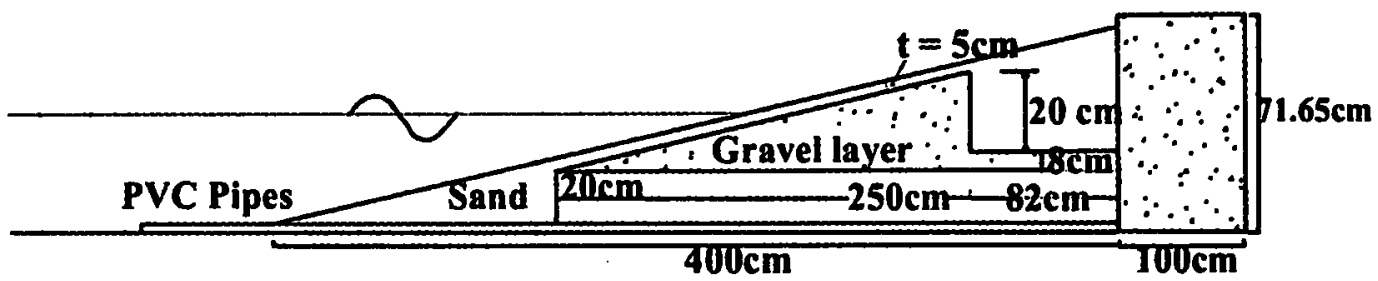

Fig 4.1 (c) $5 \mathrm{~cm}$ thick sand layer above the gravel layer

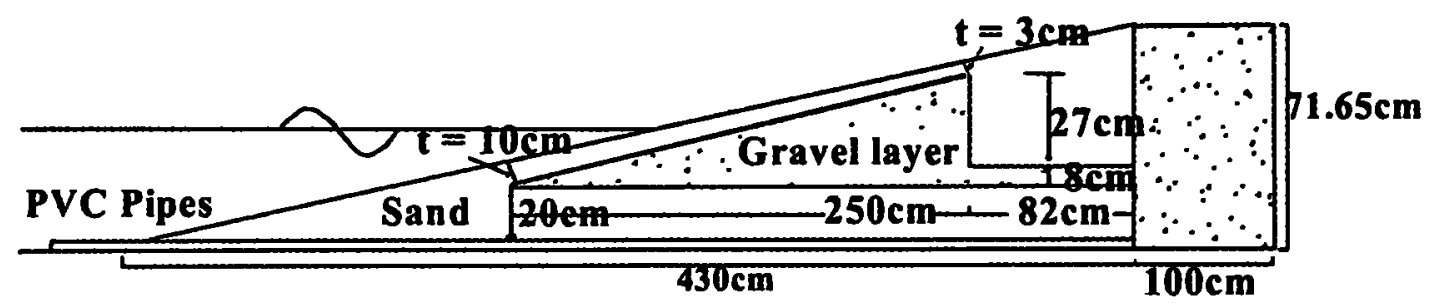

Fig 4.1 (d) 1:4.8 inclined sand layer above the gravel layer 


\section{Results and discussion}

\subsection{Results of the elevated ground water table experiment}

When the beach was subjected to erosive waves, the quantities of erosion were increased with the elevation of groundwater table. Sand was eroded from near shore region and deposited on offshore. When the beach was subjected to accretion wave condition, the quantity of deposition was decreased with the increase of ground water level. With a level of $5 \mathrm{~cm}$, five accretion waves remained on accretion but with less effect. When the level was increased to $10 \mathrm{~cm}$ all the wave conditions were converted to erosive. At maximum level of the ground water table, $13 \mathrm{~cm}$ without self-fludization of sand from seepage, the beach response was even worse.

The erosion for all the cases with groundwater tables was higher than the normal erosion for the same wave conditions. The sediment transport on swash zone was highly influenced by the beach groundwater table. Net sediment transport towards offshore has increased. Larger amounts of sediment were transported with down rush than up rush.

The results for one erosive wave condition are shown in Fig 5.1(a) to (d).

\subsubsection{Results of beach dewatering system}

The beach response to erosive waves was different for each drainage layer. When the position of the drainage layer was closer to the beach face, the erosion of the beach was increased, but at the initial stage the rate of erosion was slower than the normal beach. After the eroded depth was close to the drainage layer the complete processes were altered. It can be understood from this result that the depth of scouring is a deciding factor for optimum location of the drainage layer. Only erosive wave conditions were affected by this criterion. When the location of the drainage layer was too far from the beach face, the influence of the layer on sediment transport was negligible. It can be seen from the results that the speed of infiltration of water at the beach face is another major factor affecting the efficiency of the dewatering systems. If the results of the inclined porous layer, is clearly observed it can be seen from these results that the variation of the rate of infiltration towards onshore also has some influence on sediment transport. In this case, rate of sediment deposition at initial stage was much higher than in other cases, but the location of deposition was limited to a smaller region. Therefore, it is clear that sudden changes of beach slope has affected the result. The results for one of the erosive wave conditions are show'n in Fig. $5.2(\mathrm{a})$ to (d).

\subsection{Quantification of the results}

To compare the volume of sediment transport towards onshore or offshore directions, beach profiles were compared with the reference equilibrium profiles at the start of the experiment and 3 hour mark of each experiment. The volumes of sediments for all the cases were calculated by subtracting the deposited volume from eroded volume up to the shoreline. The shoreline was chosen as the reference line for the calculations to indicate the direction of net sediment transport. The total volume of sediment transport across the shoreline can be calculated as follows

$V=\sum_{i=0}^{i=n} \frac{1}{2}\left[\left(F_{1}\left(x_{i}\right)-F_{2}\left(x_{i_{0}}\right)\right)+\left(F_{1}\left(x_{i i}\right)-F_{2}\left(x_{i}\right)\right)\right] d x . L$

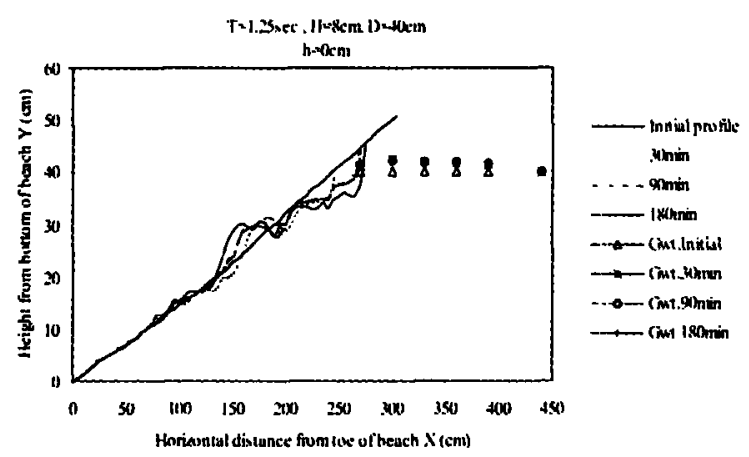

Fig. 5.1(a): Beach profile and existing ground water table (Gwt) changes with time

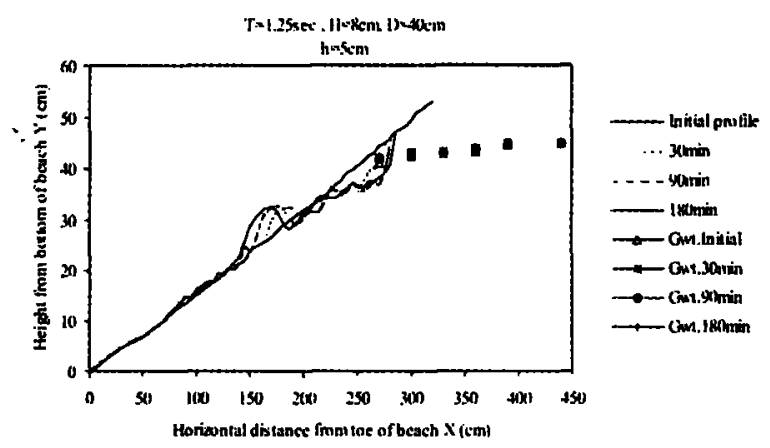

Fig. 5.1(b) Beach profile and $5 \mathrm{~cm}$ elevated ground water table ( $\mathrm{Gwt}$ ) changes with time 


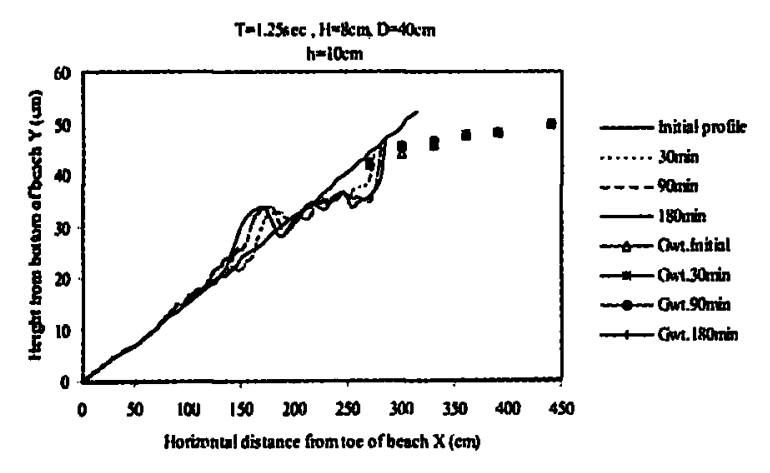

Fig.5.1(c) Beach profile and $10 \mathrm{~cm}$ elevated ground water table (Gwt) changes with time

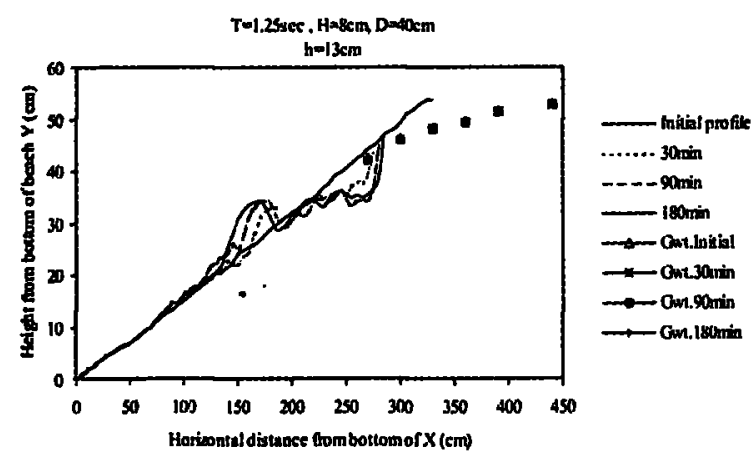

Fig.5.1 (d) Beach profile and $10 \mathrm{~cm}$ elevated ground water table (Gwt) changes with time

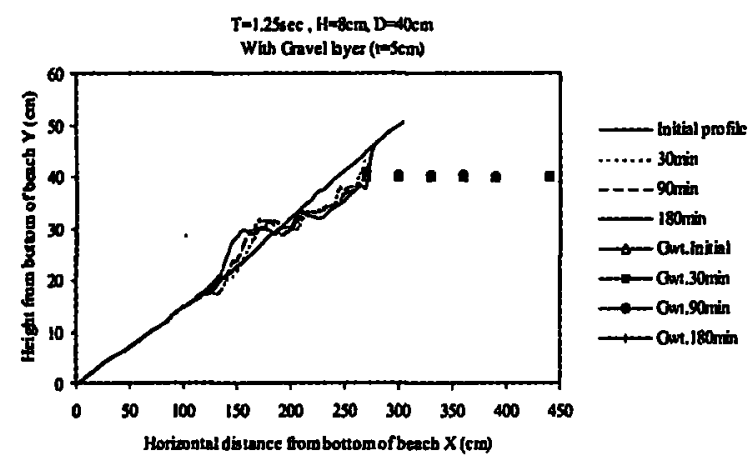

Fig. 5.2 (a): Beach profile and ground water table (Gwt) changes with time when the gravel layer is $5 \mathrm{~cm}$ below the beach face

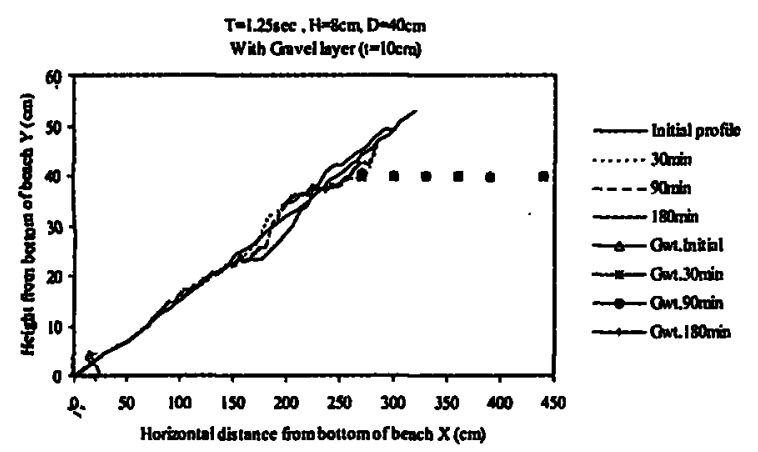

Fig. 5.2 (b): Beach profile and ground water table (Gwt) changes with time when the gravel layer $10 \mathrm{~cm}$ below the beach face

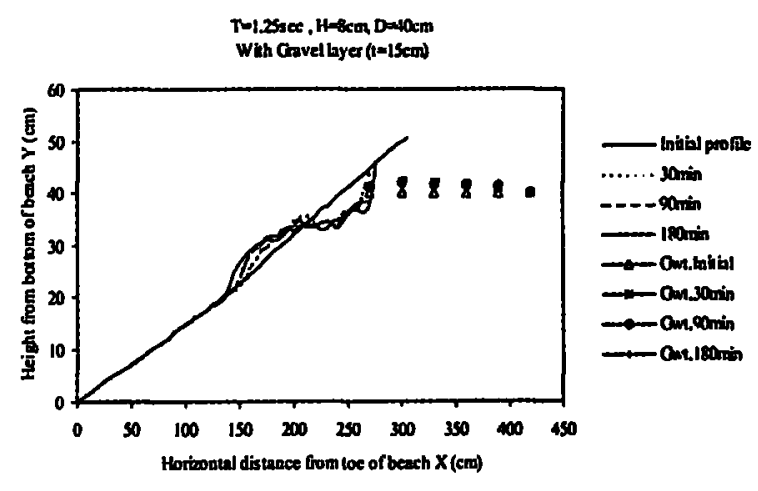

Fig. 5.2 (c): Beach profile and ground water table (Gwt) changes with time when the gravel layer $15 \mathrm{~cm}$ below the beach face

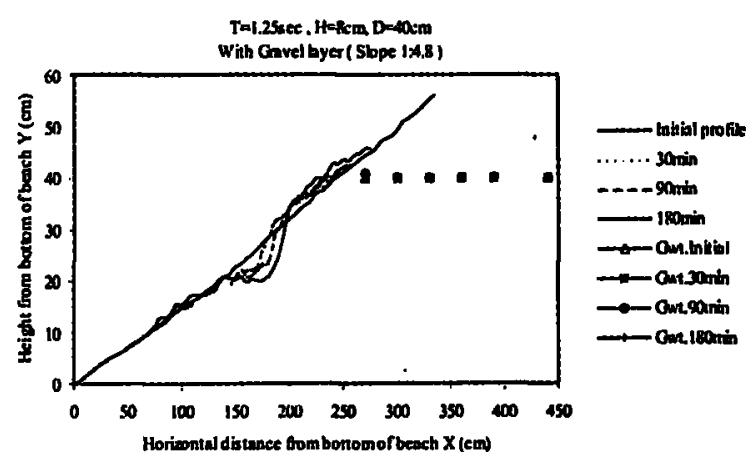

Fig. 5.2 (d): Beach profile and ground water table (Gwt) changes with time when the gravel layer 1:4.8 inclined to the beach face

Where V: Volume of net sediment transports across shoreline (deposited or eroded volume beyond the shoreline toward onshore), $F_{1}(x)$ : Initial beach profile, $\mathrm{F}_{\mathbf{2}}(\mathrm{x})$ : Final beach profile, $\mathrm{dx}$ : Increment along $X$-axis, $L /:$ Width of the flume, $i_{0}$ : Starting location of developed profile, $i_{n}$ : Shoreline 
5.3.1 Summary of the results for elevated groundwater table study

\begin{tabular}{|c|c|c|c|c|}
\hline \multicolumn{2}{|c|}{$\begin{array}{c}\text { Wave conditions }(\mathrm{T}, \mathrm{H}) / \\
\text { Elevation of groundwater table } \\
\text { (h) }\end{array}$} & \multirow[t]{2}{*}{$\begin{array}{l}\text { Eroded range / } \\
\mathrm{X} \text {-direction in } \\
\mathrm{cm}\end{array}$} & \multirow[t]{2}{*}{$\begin{array}{l}\text { Deposited range/ X- } \\
\text { direction in } \mathrm{cm}\end{array}$} & \multirow{2}{*}{$\begin{array}{l}\text { Volume of sediment } \\
\text { transport as a } \\
\text { proportion of } \\
\text { reference sediment } \\
\text { transport }\end{array}$} \\
\hline $\begin{array}{l}\mathrm{T} \text { in sec and } \mathrm{H} \text { in } \\
\mathrm{cm}\end{array}$ & $\mathrm{h}$ in $\mathrm{cm}$ & & & \\
\hline \multirow[t]{4}{*}{$T=0.80, H=6$} & $\begin{array}{c}0 \\
\text { (reference) }\end{array}$ & $270-238$ & $185-238$ & $+\operatorname{Ref}$ \\
\hline & 5 & $265-235$ & $235-185$ & 1.11 \\
\hline & 10 & $270-225$ & $170-225$ & 1.24 \\
\hline & 13 & $280-240$ & $180-240$ & 1.54 \\
\hline \multirow[t]{4}{*}{$\mathrm{T}=1.25, \mathrm{H}=8$} & $\begin{array}{c}0 \\
\text { (reference) }\end{array}$ & $284-185$ & 070-185 & $+\operatorname{Ref}$ \\
\hline & 5 & $275-185$ & $070-185$ & 1.94 \\
\hline & 10 & $285-185$ & $095-185$ & 2.27 \\
\hline & 13 & $280-175$ & $100-175$ & 2.52 \\
\hline \multirow[t]{4}{*}{$\mathrm{T}=1.00, \mathrm{H}=6$} & $\begin{array}{c}0 \\
\text { (reference) }\end{array}$ & $284-215$ & $167-215$ & $+\operatorname{Ref}$ \\
\hline & 5 & $280-210$ & $180-210$ & 1.66 \\
\hline & 10 & $280-205$ & $205-165$ & 4.11 \\
\hline & 13 & $275-235$ & $175-235$ & 4.27 \\
\hline \multirow[t]{4}{*}{$\mathrm{T}=1.00, \mathrm{H}=4$} & $\begin{array}{c}0 \\
\text { (reference) }\end{array}$ & $275-225$ & $275-225$ & $+\operatorname{Ref}$ \\
\hline & 5 & $290-200$ & $180-200$ & 2.14 \\
\hline & 10 & $290-225$ & $185-225$ & 3.57 \\
\hline & 13 & $300-175$ & $080-175$ & 4.32 \\
\hline \multirow[t]{4}{*}{$\mathrm{T}=1.25, \mathrm{H}=4$} & $\begin{array}{c}0 \\
\text { (reference) }\end{array}$ & $165-210$ & $275-210$ & - Ref \\
\hline & 5 & $210-170$ & $265-210$ & -0.59 \\
\hline & 10 & 275-195 & $150-195$ & 0.20 \\
\hline & 13 & $270-190$ & $150-190$ & 0.27 \\
\hline \multirow[t]{4}{*}{$\mathrm{T}=1.60, \mathrm{H}=4$} & $\begin{array}{c}0 \\
\text { (reference) }\end{array}$ & $180-230$ & $230-330$ & $-\operatorname{Ref}$ \\
\hline & 5 & $240-195$ & $172-195$ & -0.27 \\
\hline & 10 & $250-200$ & $140-200$ & 0.22 \\
\hline & 13 & $200-140$ & $140-200$ & 0.40 \\
\hline
\end{tabular}

Note : + refers to erosion, - refers to accretion 
5.3.2 Summary of the results for beach dewatering system

\begin{tabular}{|c|c|c|c|c|}
\hline \multicolumn{2}{|c|}{$\begin{array}{l}\text { Wave conditions }(\mathrm{T}, \mathrm{H}) / \\
\text { Distance between porous layer } \\
\text { and beach face }(t)\end{array}$} & \multirow[t]{2}{*}{$\begin{array}{l}\text { Eroded range / } \\
X \text {-direction in } \\
\mathrm{cm}\end{array}$} & \multirow[t]{2}{*}{$\begin{array}{l}\text { Deposited range/ } \\
\text { X-direction in } \\
\mathrm{cm}\end{array}$} & \multirow{2}{*}{$\begin{array}{l}\text { Volume of sediment } \\
\text { transport as a } \\
\text { proportion of } \\
\text { reference sediment } \\
\text { transport }\end{array}$} \\
\hline $\begin{array}{l}\mathrm{T} \text { in sec and } \mathrm{H} \text { in } \\
\mathrm{cm}\end{array}$ & $\mathrm{t}$ in $\mathrm{cm}$ & & & \\
\hline \multirow[t]{5}{*}{$\mathrm{T}=0.80, \mathrm{H}=6$} & $\begin{array}{c}0 \\
\text { (reference) }\end{array}$ & $270-238$ & $185-238$ & $+\operatorname{Ref}$ \\
\hline & 5 & $260-235$ & $175-235$ & 2.18 \\
\hline & 10 & $228-260$ & $200-228,260-270$ & -0.10 \\
\hline & 15 & $270-225$ & $190-225$ & 0.91 \\
\hline & Inclined & $250-235$ & $270-250,220-235$ & -0.05 \\
\hline \multirow[t]{5}{*}{$\mathrm{T}=1.25, \mathrm{H}=8$} & $\begin{array}{c}0 \\
\text { (reference) }\end{array}$ & $284-185$ & $070-185$ & + Ref \\
\hline & 5 & $280-185$ & $110-185$ & 0.61 \\
\hline & 10 & $220-150$ & $220-300$ & -2.04 \\
\hline & 15 & $275-205$ & $140-205$ & 0.99 \\
\hline & Inclined & $140-200$ & $270-200$ & -1.29 \\
\hline \multirow[t]{5}{*}{$\mathrm{T}=1.00, \mathrm{H}=6$} & $\begin{array}{c}0 \\
\text { (reference) }\end{array}$ & $284-215$ & $167-215$ & $+\operatorname{Ref}$ \\
\hline & 5 & $255-210$ & $210-165,280-255$ & -1.80 \\
\hline & 10 & $250-210$ & $280-250,210-160$ & -0.55 \\
\hline & 15 & $280-210$ & $180-210$ & 1.08 \\
\hline & Inclined & $210-248$ & $248-270,195-210$ & -0.83 \\
\hline \multirow[t]{4}{*}{$\mathrm{T}=1.00, \mathrm{H}=4$} & $\begin{array}{c}0 \\
\text { (reference) }\end{array}$ & $275-225$ & $275-225$ & \\
\hline & $\begin{array}{c}5 \\
10\end{array}$ & $190-170^{-}$ & 280-190 & -0.08 \\
\hline & 15 & - & - & - \\
\hline & Inclined & $275-210$ & $165-210$ & -1.72 \\
\hline \multirow[t]{5}{*}{$\mathrm{T}=1.25, \mathrm{H}=4$} & $\begin{array}{c}0 \\
\text { (reference) }\end{array}$ & $165-210$ & $275-210$ & -Ref \\
\hline & 5 & $210-125$ & $270-210$ & -2.15 \\
\hline & 10 & $210-150$ & $275-210$ & -2.08 \\
\hline & 15 & $275-210$ & $135-210$ & -1.99 \\
\hline & Inclined & $215-275$ & $152-215$ & -2.08 \\
\hline \multirow[t]{5}{*}{$\mathrm{T}=1.60, \mathrm{H}=4$} & $\begin{array}{c}0 \\
\text { (reference) }\end{array}$ & $180-230$ & $230-330$ & $-\operatorname{Ref}$ \\
\hline & 5 & $300-220$ & $140-220$ & -1.34 \\
\hline & 10 & $220-150$ & $325-220$ & -1.21 \\
\hline & 15 & $320-220$ & $160-220$ & -1.58 \\
\hline & Inclined & $215-310$ & $155-215$ & -1.30 \\
\hline
\end{tabular}

Note: + refers to erosion, - refers to accretion 


\section{Conclusion}

The influence of beach water table on sediment transport cannot be neglected. The elevation of groundwater table was related to the quantity of erosion. With the influence of the elevated groundwater table, accretion waves were converted into erosive waves. The groundwater table has affected the sediment transport in the swash zone. The sediment transport with up rush was much less than sediment transport with down rush and, as a result of these processes, sediment transport towards offshore has enhanced. Larger amounts of sediment were transported as bed load towards offshore than onshore.

The functions of the drainage system were dependent on several parameters, such as location of the drainage layer, souring depth of the wave, rate of percolation of wave run up on the beach face, etc. The most suitable location of our set up was $10 \mathrm{~cm}$ bellow the beach face. It can be concluded from these results that by introducing a fast drainage system, beach erosion from erosive wave can be reduced. But the location of installation should be decided considering above parameters with the field conditions.

\section{References}

1. Ian L. Turner and Peter Nielsen, (1997) "Rapid water table fluctuations within the beach face: Implications for swash zone sediment mobility?" Proceeding of Coastal Engineering 32 (1997)" ELSEVIER, Pp 45-59.

2. Tae- Myoung Oh and Robert G. Dean, (1994) "Effects of controlled water table on beach profile dynamics" Proceedings of Coastal Engineering 1994" Pp 2449-2459.

3. Hiroshi Kanazawa, Fumihiko Matsukawa, Kazumasa Katoh and Iwao Hasegawa (1996) "Experimental Study on the effect of gravity drainage system on beach stabilization" Proceedings of Coastal Engineering 1996. Pp 26402653.

4. Kazumasa Katoh and Shin-ichi Yanagishima (1996). "Field experiment on the effect of gravity drainage system on beach stabilization" Proceedings of Coastal Engineering 1996. Pp 26542665.
5. Bruce J. Hegge and Gerhard Masselink (1991) "Ground water table responses to wave run-up: An experimental study from western Australia" Journal of Coastal Research, Vol. \&, No.3, Pp 623634.

6. Hong- Yoon Kang and Peter Nielsen.(1996) "Watertable Dynamics in Coastal Areas" Proceedings of Coastal Engineering. Pp 46004608.

7. Andrew J. Baird, Traavis E. Mason, and Diane P. Horn (1996). "Mechanisms of beach ground water and swash interaction" Proceedings of Coastal Engineering. Pp 4121-4133.

8. I. Li, D. A. Barry, J.Y. Parlange, and C. B. Pattiaratchi.(1997) " Beach water table fluctuations due to wave run-up: Capillary effects." Water Resources Research, Vol. 33, No. 5, Pp 935-945.

9. Peter Nielson, and David J. Hanslow. (1991)" Wave run up distributions on natural beaches" Journal of Coastal Research, Vol. 7, No.4, Pp 11391152.

10. Michio Sato, Sadakatsu Hata and Masahiro Fukushima. (1994) "An experimental study on beach transformation due to waves under the operation of coastal drain system" Proceeding of Coastal Engineering. Pp 2571-2581.

11. Ryuichiro Nishi and Nicholas C. Kraus (1996). “ Mechanism and calculation of sand dune erosion by storms" Proceeding of Coastal Engineering. Pp 3034-3043.

12. Ian L. Turner (1998) "Monitoring groundwater dynamics in the littoral zone at seasonal, storm, tide and swash frequencies" Proceeding of Coastal Engineering 35. Pp 1-16

13. M.R Gourlay (1992) "Wave set-up, wave run-up and beach water table: Interaction between surf zone hydraulic and groundwater hydraulics" Proceedings of Coastal Engineering 17. Pp 93-144.

14. Peter Nielsen and Scott L. Dunn "Manometer tubes for coastal hydrodynamics investigations" Proceedings of Coastal Engineering 35. Pp 73-84.

15. James M. Parkers (1991) "New dredging technology for inlets and beaches: move sand to the pump" Coastal sediments. Pp 194.3-1954.

16. Tomoya Shibayama (1998) "Modelling of timedependent sand transport at the bottom boundary layer in the surf zone" Coastal engineering journal, Vol.40, No.3 Pp 241-263.' 
17. M. C. Quick (1990) "Onshore-offshore sediment transport on beaches" Proceedings of Coastal Engineering, $15 \mathrm{Pp}$ 313-332.

18. S. Takahashi, S. Yamamoto and H. Miura(1994) "Fundamental characteristics of a new wave absorbing system using sand - liquefaction" Proceedings of Coastal Engineering Pp 2699-2714. 